\title{
Polymeric Nanocarriers for Effective Synergistic Action of Sorafenib Tosylate and Gold-sensitized Gamma Radiation Against HepG2 Cells
}

\author{
Firas Sukkar' \\ Medhat Shafaa' \\ Mohamed El-Nagdy' \\ Wael Darwish ${ }^{2}$ \\ 'Physics Department, Faculty of Science, \\ Helwan University, Cairo, Egypt; \\ ${ }^{2}$ Department of Polymers and Pigments, \\ National Research Centre, Giza, I2622, \\ Egypt
}

Correspondence: Wael Darwish Department of Polymers and Pigments, National Research Centre, Elbohouth Street, Dokki, Giza, 12622, Egypt

Tel +0201092336I76

Fax +2023337I635

Email wmdarwish55@gmail.com
Purpose: One of the key parameters towards effective and synergistic combinatorial anticancer therapeutic models is the nanocarrier. Nearly all previous studies have been limited to one nanocarrier for one drug. However, a comparative study on two polymeric nanocarriers for the same drug against the same cancer cell and under the same conditions helps to rationalize the properties of each polymeric nanocarrier to the effectiveness of the drugloaded nanocapsules.

Methods: In this study, two of biocompatible polymers, namely poly lactic-co-glycolic acid (PLGA) and polye-caprolactone (PCL), were used for co-delivery of sorafenib tosylate and gold nanoparticles $(\mathrm{G})$.

Results: The anticancer effects of sorafenib tosylate (ST) combined with gold-sensitized radiation therapy were studied and rationalized to the physicochemical properties of each nanocarrier. Both models inhibited the proliferation of HepG2 cells via cell cycle arrest. The use of PCL and PLGA as nanocarriers for the proposed combined (chemo-radio) therapeutic model reduced the viability of HepG2 cells to $26 \%$ and $8 \%$, respectively. PCL and PLGA models showed high necrosis levels (15.1 and 16.2, respectively).

Conclusion: Both PCL and PLGA are good nanocarriers for the proposed combined model. Compared to PCL NPs, PLGA NPs showed enhanced release, higher cytotoxicity and higher necrosis levels.

Keywords: biodegradable polymers, drug delivery, flow cytometry, PLGA, PCL, radiotherapy

\section{Introduction}

Anticancer combination therapy demonstrated superior safety and efficacy to monotherapies and, therefore, has emerged as an important treatment paradigm in the curative management of multidrug resistant cancer cells. ${ }^{1}$ Nanocarriers based on biodegradable polymers hold impressive promise for co-delivery and combination of diverse therapies against multidrug-resistive tumor cells. ${ }^{2}$ Drug-loaded polymeric nanocapsules are featured with excellent water dispersibility, sustained drug release, and enhanced tumor targeting. ${ }^{3}$ Further, polymeric nanoparticles minimize the nonspecific binding of the drugs with blood proteins. ${ }^{4}$ Previously, polymeric nanocarriers were utilized to load one drug only, ${ }^{5}$ which may be less potent against tumor cells, especially multidrug resistant (MDR) cells. ${ }^{6}$ Eventually, single-drug nanoparticles cannot inhibit recurrence or metastasis of cancer. Recently, polymer-based synergistic drug combinations have gained momentum in cancer therapy because of their superior 
therapeutic benefits to the classical monotherapeutics used in clinical practice. ${ }^{7}$ For example, cancer monotherapy of hepatocellular carcinoma (HCC) in the clinic using the antiangiogenic drug sorafenib tosylate (ST) produces relatively low tumor response rates in the majority of patients due to poor aqueous solubility and hepatic first-pass effect of ST and its tosylate derivative. Therefore, PLGA nanoparticles were used to co-deliver ST and doxorubicine. ${ }^{8}$ Gan et al reported on the enhanced delivery of sorafenib with antiGPC3 antibody-conjugated with pluronic P123 for targeted delivery of HCC. ${ }^{9}$ Another example for monotherapy is radiotherapy in which the deposited energy can cause damage to the healthy tissues nearby the tumor. The need of prior administration of radiosensitizer such as gold nanoshapes is essential to enhance the radiobiological response of the cancer cells. Combination of chemotherapy with gold-sensitized radiotherapy has recently developed to achieve synergistic anticancer actions. ${ }^{10}$ Importantly, polymeric nanocarriers can co-load and co-deliver both the chemotherapeutic and the radiosensitizer regardless of their physical and chemical properties. ${ }^{11,12}$ Novel methods, such as electrospining and electrospraying, have been recently developed for creating polymeric nanocarriers of favorable biomedical characteristics. For example, Wang et $\mathrm{al}^{13}$ reported that electrospun Janus zein-PVP nanofibers provide a two-stage controlled release of poorly water-soluble drugs. Also, electrospraying method was used for preparation of drug-zein@lipid hybrid nanoparticles characterized with sustained drug release. ${ }^{14}$

In this work, we studied the effects of the polymeric nanocarrier on the therapeutic benefits of a combinatorial (chemo-radio) model against hepatocellular carcinoma. Two biocompatible polymers namely, poly(D,L-lactide-coglycolide) (PLGA) and polye-caprolactone (PCL) were selected for this study because they are preferentially used for production of monodispersed nanoparticles featured with high drug-payload, sustained drug release, tumor targeting and biodegradability. ${ }^{15,16}$ Gold nanoparticles were selected as a radiosensitizer due to its biocompatibility and its ability to localize the ionizing radiation in the tumor sites and thus, minimizing the radiation-induced damage of the normal tissues nearby the tumor. ${ }^{17}$ GNPs have been used as radiosensitizer in several combination therapeutic models. ${ }^{18}$ The synergistic actions of the prepared models against HepG2 cells were investigated via cell viability assay, flow cytometry and mitochondrial membrane potential assay.

\section{Materials and Methods}

Monodispersed gold nanoparticles were prepared according to literature procedures ${ }^{19}$ with slight modifications. In brief, a $100 \mathrm{~mL}$ aqueous solution of $\mathrm{HAuCl}_{4} 4 \mathrm{H}_{2} \mathrm{O}(1 \mathrm{mM}$, $99.99 \%$, Sigma) was brought to the boil with vigorous stirring, and then $10 \mathrm{~mL}$ of sodium citrate tribasic dihydrate solution $(38.8 \mathrm{mM})$ was quickly added. After the solution color changed to deep red, the solution was refluxed for an additional $15 \mathrm{~min}$. Ten milligrams of poly(ethylene glycol) methyl ether thiol (mPEG-SH) $\left(\mathrm{M}_{\mathrm{W}}=6000\right.$, Sigma) was added to $10 \mathrm{~mL}$ of above aqueous solution, and stirred for $24 \mathrm{~h}$ to complete the ligand exchange (citrate to PEG).

\section{Loading of Gold and/or Sorafenib Tosylate in PCL}

Sorafenib tosylate was a product of Sigma-Aldrich. In brief, $3 \mathrm{mg}$ sorafenib tosylate and $24 \mathrm{mg}$ of poly $\varepsilon$ caprolactone (PCL, $\mathrm{M}_{\mathrm{w}} \sim 14,000$, Sigma) were dissolved in $3 \mathrm{~mL}$ of dry tetrahydrofuran (THF) until a clear solution was obtained. This solution was slowly added to a strongly stirred $15 \mathrm{~mL}$ of PVA aqueous solution (1\%) previously passed through a $0.45 \mu$ microfilter. For preparation of gold containing nanoparticles, the organic solution was dropped to PVA solution containing the desired concentration of gold. As given in Table 1, the ratios of polymer/ drug/organic solvent/water were (1/8/1/5, respectively). After vortexing for $5 \mathrm{~min}$, the samples were sonicated (25 W, 20 cycles) using a microtip-probe sonicator while the sample was cooled over an ice bath. THF was then

Table I Polymer-based Formulations Studied in This Work

\begin{tabular}{|l|c|c|c|c|c|}
\hline Formulation & ST (mg) & GNPs (mg) & Polymer & Org. Solvent & Aq. PVA (I\%) \\
\hline ST/PCL & $3 \mathrm{mg}$ & - & $24 \mathrm{mg}$ & $3 \mathrm{~mL}$ & $15 \mathrm{~mL}$ \\
G/PCL & - & 5 & $24 \mathrm{mg}$ & $3 \mathrm{~mL}$ & $15 \mathrm{~mL}$ \\
G+ST/PCL & $3 \mathrm{mg}$ & 5 & $24 \mathrm{mg}$ & $3 \mathrm{~mL}$ & $15 \mathrm{~mL}$ \\
ST/PLGA & $3 \mathrm{mg}$ & - & $24 \mathrm{mg}$ & $3 \mathrm{~mL}$ & $15 \mathrm{~mL}$ \\
G/PLGA & - & 5 & $24 \mathrm{mg}$ & $3 \mathrm{~mL}$ & $15 \mathrm{~mL}$ \\
G+ST/PLGA & $3 \mathrm{mg}$ & 5 & $24 \mathrm{mg}$ & $3 \mathrm{~mL}$ & $15 \mathrm{~mL}$ \\
\hline
\end{tabular}


evaporated under reduced pressure at room temperature. To remove the large capsules, samples were subjected to centrifugation (3000 rpm, $5 \mathrm{~min}$.). The supernatant containing the small and uniform nanocapsules was passed through a $0.45 \mu \mathrm{M}$ filter to remove the nonencapsulated drug. ${ }^{20}$ Drug-loaded nanocapsules were collected by highspeed centrifugation $(13,000 \mathrm{rpm}, 20 \mathrm{~min})$, washed twice with PBS ( $\mathrm{pH}$ 7.4). The nanoparticles were redispersed in $1 \%$ sucrose aqueous solution, freeze dried, and kept at $-20^{\circ} \mathrm{C}$ until used.

\section{Loading of Gold and/or Sorafenib Tosylate in PLGA}

These nanocapsules were prepared as described for PCL NPs, except acetone was used as solvent for both poly(D, L-lactide-co-glycolide) acid terminated (PLGA, Mw 7000-17,000 (50\%:\%50\%, Sigma) and ST) (Table 1).

\section{Drug-loading and Encapsulation Efficiency}

The supernatant collected during synthesis and purification of the nanoparticles was analyzed for unloaded (free) drug. This supernatant was analyzed for sorafenib tosylate content by standard HPLC method, where a mobile phase composition consisting of acetonitrile and water (containing orthophosphoric acid, $\mathrm{pH} 4.1$ ) at $65: 35 \mathrm{v} / \mathrm{v}$ at a flow rate of $0.8 \mathrm{~mL} / \mathrm{min}$ with UV detection at $265 \mathrm{~nm}^{21}$ The amount of encapsulated ST was calculated by abstraction the drug concentration in the supernatant from the total drug amount added in the experiment. For determination of gold content in the prepared nanocapsules, an accurate weight of the lyophilized nanoparticles was sonicated in chloroform for 10 minutes to dissolve the polymers followed by centrifugation (10.000 rpm, $10 \mathrm{~min})$, digestion of the residual gold in aqua regia and sampling in precalibrated atomic absorption spectrometer. ${ }^{22}$ Drug loading (DL, \%) and encapsulation efficiency (EE, \%) were calculated according to equations 1 and 2 .

$$
\text { Drug loading }(\mathrm{mg} / \mathrm{g})=\frac{\text { Drug amount in NPs }}{\text { Weight of NPs powder }}
$$

Encapsulation efficiency $(\%)=\frac{\text { Drug loaded in NPs }}{\text { Total drug added }} \times 100$

\section{In Vitro Release Profile}

The release profiles of sorafenib tosylate (ST) from the ST/PCL and ST/PLGA nanoparticles were studied as follows: $10 \mathrm{mg}$ of the lyophilized powder was dispersed in
$4 \mathrm{~mL}$ of PBS (pH 7.4) and put in dialysis tubing (MWCO $3 \mathrm{KDa}$ ). The bag was immersed in $20 \mathrm{~mL}$ of dialysate (PBS, pH 7.4) under air bath thermostat $\left(37 \pm 0.5^{\circ} \mathrm{C}\right.$, $180 \mathrm{rpm})$. At different time intervals (1-72 h), exactly $1 \mathrm{~mL}$ of the dialysate was taken out and replaced with $1 \mathrm{~mL}$ of fresh PBS. The dialysate aliquots were analyzed for ST content and gold content by HPLC technique and atomic absorption spectroscopy, respectively as previously described.

\section{Cell Viability Assay}

Human hepatoma HepG2 cells were obtained from American Type Culture Collection and were cultured at $37^{\circ} \mathrm{C}$ in RPMI-1640 medium supplemented with $10 \%$ fetal bovine serum (FBS), L-glutamine $(200 \mathrm{mM})$, penicillin $(100 \mathrm{U} / \mathrm{mL})$, streptomycin $(100 \mu \mathrm{g} / \mathrm{mL})$, and HEPES buffer (1 M) (All from Biowest, Nuaillé, France). When reaching confluence, monolayer cells were rinsed with phosphate buffered saline (PBS) and harvested by trypsin/EDTA (Biowest) treatment. After treatment of cells with the serial concentrations of the formulations to be tested and incubation for $48 \mathrm{~h}$ at $37^{\circ} \mathrm{C}$, the plates were examined under the inverted microscope before MTT assay.

\section{Cell Irradiation}

After incubation of the cells with different formulations for $48 \mathrm{~h}$, the media was replaced with fresh media and the cells were irradiated with different radiation doses ( 2 and 4 Gy) by cesium- 137 source and incubated at $37^{\circ} \mathrm{C}$ for 24 h. The source-to-cell surfaces distance was adjusted at $100 \mathrm{~cm}$ for the irradiated culture plates at a radiation field size of $15 \times 15 \mathrm{~cm}^{2}$. Twenty-four hours postirradiation, cell viability was assessed by MTT assay. Sensitization enhancement ratio (SERs) of various treatment groups was calculated and compared using HepG2 cells. SERs were calculated by dividing the surviving fraction of the irradiated cells in the absence of gold on the surviving fraction in presence of gold for each dose of radiation according to standard protocols.

\section{Cell Apoptosis Analysis by Flow Cytometry}

For apoptosis analysis, HepG2 cells were cultured and incubated overnight at $37^{\circ} \mathrm{C}$ with $5 \% \mathrm{CO}_{2}$. Cells were then incubated with prepared nanoformulations for $48 \mathrm{~h}$, where concentrations of gold and sorafenib tosylate were 
kept constant in all formulations. Selected test samples were irradiated by Cs-137 (6 Gy). The induced apoptosis was predicted $96 \mathrm{~h}$ post irradiation. After trypsinization and centrifugation of the cells, pellets were thoroughly rinsed with PBS ( $\mathrm{pH}$ 7.4) and resuspended in a binding puffer. Exactly $5 \mu \mathrm{L}$ of FITC annexin V and $5 \mu \mathrm{L}$ PI were added $\mathrm{t}$ samples. Afterward, cells were gently vortexed and incubated at RT $\left(24^{\circ} \mathrm{C}\right)$ for $20 \mathrm{~min}$ in the dark. 400 $\mu \mathrm{L}$ of $1 \times$ binding buffer were added to each tube and then cells were analyzed using flow cytometry within $1 \mathrm{~h}$. and then cells were checked using a FACS Calibur (Becton Dickinson, USA) and CellQuest Pro Software (Becton Dickinson, USA), with emission filters set at BP530/30 and BP585/42 nm for FITC annexin V and propidium iodide labels, respectively. Ten thousand cells per sample were measured for both fluorescence intensities. Before measurements, control samples (cells without labeling and cells labeled with either FITC annexin V or propidium iodide) were used to optimize device measurement parameters (fluorescence threshold and compensation). ${ }^{23}$

\section{Cell Cycle Analysis by Propidium lodide (PI) Staining}

The cell analysis experiments were carried out according the standard protocol. ${ }^{24}$ After treatment, HepG2 cells were harvested and washed twice in PBS. Cells were fixed with $70 \%$ ethanol and incubated with $1 \mathrm{mg} / \mathrm{mL}$ Ribonuclease A (Sigma-Aldrich, St Louis, MO, USA) for $30 \mathrm{~min}$ at $37^{\circ} \mathrm{C}$. Afterwards, HepG2 cells were washed twice in PBS and stained with PI. DNA content was analyzed by flow cytometry on a FACSCalibur ${ }^{\mathrm{TM}}$ Cytometer (Becton and Dickinson, Heidelberg, Germany). Data analysis was performed using CellQuest software (Becton and Dickinson, Heidelberg, Germany).

\section{Mitochondrial Membrane Potential (MMP)}

The MMP was tagged using an NIR Mitochondrial Membrane Potential Assay kit (Abcam 113852) according to the manufacturer's protocol. In brief, HepG2 cells $\left(2.5 \times 10^{5}\right.$ cells/well $)$ were seeded into 24 -well plates and incubated in a carbon dioxide incubator at $37^{\circ} \mathrm{C}$ for 20 h. HepG2 cells were treated with the prepared nanoformulations comprising $5 \mu \mathrm{M}$ of sorafenib tosylate and $0.3 \mu \mathrm{M}$ of gold nanoparticles for $72 \mathrm{~h}$. MitoNIR Dye (200X, $5 \mu \mathrm{L} / \mathrm{mL}$ ) was added to each sample, followed by incubation at $37^{\circ} \mathrm{C}$ for $25 \mathrm{~min}$. Finally, the cells pellets was resuspended in $1 \mathrm{~mL}$ of assay buffer, and the fluorescence intensity was monitored using flow cytometry in the FL4 channel $\left(\lambda_{\text {Excitation }} / \lambda_{\text {Emission }}=635 / 660 \mathrm{~nm}\right)$.

\section{Statistical Analysis}

All experiments were repeated three times $(n=3)$ and differences in the data were evaluated with one way ANOVA test. The data are given as a mean \pm standard deviation (SD) at statistically significant values $(P<0.05)$.

\section{Results and Discussion}

In this work, we studied the influence of the nature of the polymeric nanocarrier on the anticancer actions of combinatorial treatment model, comprising the chemotherapeutic sorafenib tosylate (ST) and gold-sensitized $\gamma$-radiation, on HepG2 cells. Two biocompatible/biodegradable polymers, namely poly lactic-co-glycolic acid (PLGA) and poly $\varepsilon-$ caprolactone (PCL), were selected for this study. PLGA NPs and PCL NPs were used to co-load sorafenib tosylate and gold radiosensitizer. Pegylated gold nanoparticles were used as a radiosensitizer capable to enhance the radiobiological response of HepG2 cells and thus reduce the effective radiotherapeutic dose. The key parameter in the success of such a combinatorial model is the nanocarrier selection. The nanocarrier should be characterized with high loading and moderate release kinetics of both the drug and the radiosensitizer. Data driven from apoptosis assay, cell cycle assay and mitochondrial membrane potential assay provide important information about the effect of the nature of polymeric nanocarrier on the chemo- and radiotherapeutic indices of HepG2 cells.

\section{Pegylated Gold Nanoparticles}

TEM image of the prepared GNPs (Figure 1A) showed monodispersed spherical nanoparticles of mean diameter $16 \mathrm{~nm}$. Extinction spectra of the prepared GNPs showed an extinction spectrum at $520 \mathrm{~nm}$ (Figure 1B). DLS measurements of GNPs colloid showed average hydrodynamic diameter of $22 \pm 2.1 \mathrm{~nm}$. According to $\zeta$ potential measurements, GNPs have a negative surface charge of $-16.42 \mathrm{mV}$.

\section{Polymeric Nanoformulations}

In this work, the hydrophilic radiosensitizer (gold nanoparticles, GNPs) and/or the hydrophobic anticancer drug (sorafenib tosylate, ST) were efficiently loaded in both PCL NPs and PLGA NPs via nanoprecipitation method. High encapsulation efficiencies of both ST and GNPs 

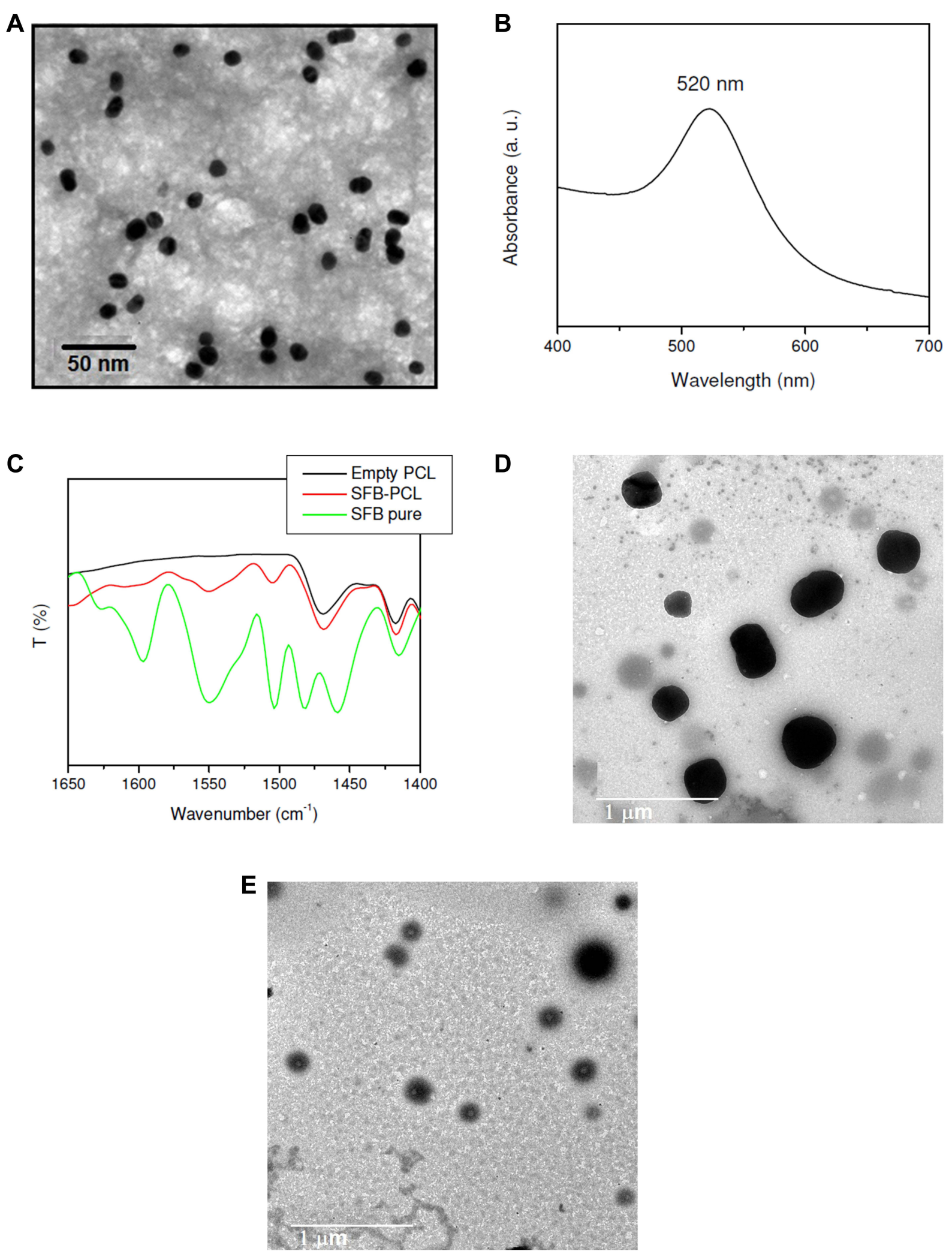

Figure I TEM image of GNPs (A), UV-Vis spectrum of GNPs (B), FTIR spectra of pure ST, empty PCL NPs and ST/PCL NPs (C), TEM images of G+ST/PCL (D) and G+ST/ PLGA (E). 
Table 2 Physical and Morphological Properties of the Prepared Nanoparticles

\begin{tabular}{|c|c|c|c|c|c|c|c|}
\hline \multirow[t]{2}{*}{ Nanoparticles } & \multirow[t]{2}{*}{ HD $\pm S D(n m)$} & \multirow[t]{2}{*}{ PDIESD } & \multirow[t]{2}{*}{ Zeta $\pm S D(m V)$} & \multicolumn{2}{|c|}{ Drug loading (mg/g) } & \multicolumn{2}{|c|}{ EE (\%) } \\
\hline & & & & ST & GNPs & ST & GNPs \\
\hline Empty PLGA & $205.5 \pm 3.1$ & $0.022 \pm 0.05$ & $-20.1 \pm 1.9$ & - & - & - & - \\
\hline ST/PLGA & $222.1 \pm 4.4$ & $0.172 \pm 0.11$ & $-22.8 \pm 0.6$ & $54.2 \pm 2.2$ & - & $40.1 \pm 2.6$ & - \\
\hline G/PLGA & $256.9 \pm 2.9$ & $0.152 \pm 0.08$ & $-26.1 \pm 0.9$ & - & $44.1 \pm 2.3$ & - & $61.2 \pm 2.5$ \\
\hline $\mathrm{ST}+\mathrm{G} / \mathrm{PLGA}$ & $299.8 \pm 6.2$ & $0.216 \pm 0.13$ & $-27.5 \pm 2.2$ & $50.6 \pm 3.4$ & $38.2 \pm 1.1$ & $38.9 \pm 1.6$ & $55.8 \pm 1.3$ \\
\hline Empty PCL & $265.4 \pm 4.2$ & $0.205 \pm 0.21$ & $-14.1 \pm 1.9$ & - & - & - & - \\
\hline ST/PCL & $276.1 \pm 3.2$ & $0.256 \pm 0.27$ & $-12.8 \pm 0.6$ & $44.6 \pm 4.5$ & - & $38.5 \pm 1.8$ & - \\
\hline $\mathrm{G} / \mathrm{PCL}$ & $314.9 \pm 3.9$ & $0.298 \pm 0.18$ & $-13.9 \pm 0.9$ & - & $35.2 \pm 2.9$ & - & $21.5 \pm 2.6$ \\
\hline $\mathrm{ST}+\mathrm{G} / \mathrm{PCL}$ & $355.8 \pm 6.4$ & $0.282 \pm 0.14$ & $-14.8 \pm 1.2$ & $38.9 \pm 3.9$ & $29.6 \pm 3.1$ & $33.8 \pm 1.6$ & $19.8 \pm 2.2$ \\
\hline
\end{tabular}

Note: Data represent the mean $\pm-S D, n=3$.

Abbreviations: ALG, alginate; EE, encapsulation efficiency; HD, hydrodynamic diameter assessed by DLS; HG, hexagonal gold nanoparticles; ST, sorafenib tosylate; PDI, polydispersity index; SD, standard deviation; Zeta, zeta potential.

(Table 2) were obtained via optimizing the reaction conditions (drug to polymer and organic to aqueous rations) in our laboratory. The morphological and physicochemical properties of the prepared nanoprobes were studied by FTIR, TEM, DLS, zeta-potential analyzer, and DSC. FTIR spectra of ST and ST/PCL NPs (Figure 1C) exhibited the characteristic vibrations of ST in the range of (1400-1650 $\mathrm{cm}^{-1}$ ) for pure ST and ST-loaded nanoparticles. These bands were not observed in FTIR of empty polymeric nanoparticles. Similar trend was observed for
PLGA NPs. According to TEM images (Figure 1D and E), PLGA NPs exhibited monodispersed spherical nanoparticles with mean diameters of 190, 200, 230, $260 \mathrm{~nm}$ for empty PLGA NPs, ST/PLGA NPs, G/PLGA NPs, and G +ST/PLGA NPs, respectively. PCL NPs nanoparticles are relatively larger in size with mean diameters of 240, 253, 289, $311 \mathrm{~nm}$ for empty PCL NPs, ST/PCL NPs, G/PCL NPs, and G+ST/PCL NPs, respectively. Results of dynamic light scattering (DLS) measurements of the prepared nanoparticles are shown in (Figure 2) and the data
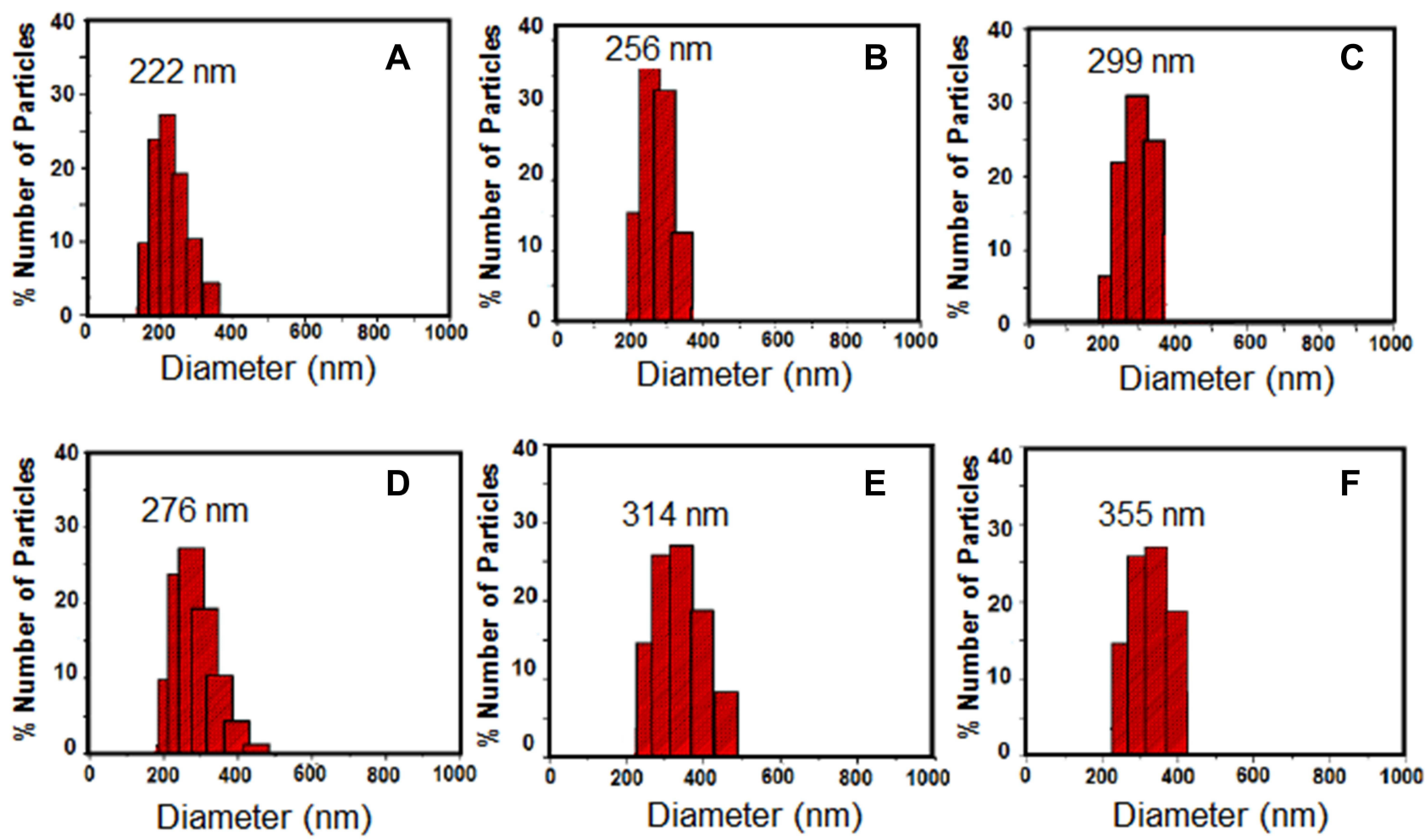

Figure 2 Results of DLS measurements of the prepared nanoparticles: (A) ST/PLGA NPs, (B) G/PLGA NPs, (C) G+ST/PLGA NPs, (D) ST/PCL NPs, (E) G/PCL NPs, (F) G + ST/PCL NPs. 
are listed in (Table 2). PLGA NPs displayed hydrodynamic diameters in the range of 205-300 nm, while PCL NPs displayed a higher range of 265-355 nm. All nanoparticles showed a narrow size distribution (polydispersity index PDI $<0.3$ ) and negative zeta potential (Table 2). The conditions were optimized in our laboratory with respect to drug to polymer and water to organic solvent ration in order to produce nearly monodispersed nanoparticles with high drug loading and encapsulation efficiency (Table 2). The prepared nanoformulations are physically stable, due to the negative surface charges, and no significant changes in size, zeta potential, or drug content were observed one month after preparation. Stability was further monitored by observing any changes in the extinction spectra of ST and GNPs in all formulations before in vitro studies. Results of DSC analysis of pure ST and the lyophilized nanoparticles (empty PCL, empty PLGA NPs, ST/PCL, and ST/ PLGA) are shown in Figure 3. DSC measurements were carried out to demonstrate the possible physical or chemical interactions of the drug with the nanocarrier. DSC thermogram of pure ST (Figure 3A) showed a sharp endothermic peak centered at $211.32^{\circ} \mathrm{C}$

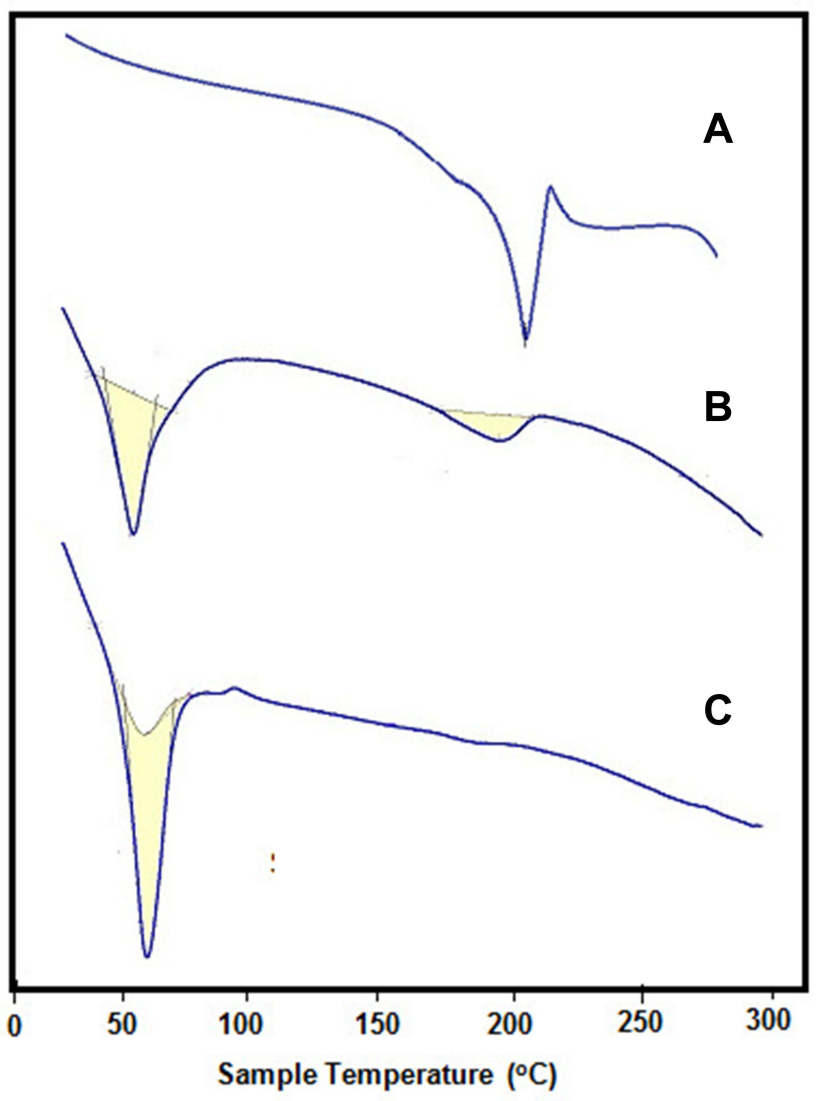

Figure 3 DSC thermograms of (A) pure ST, (B) G+ST/PCLA, (C) G+ST/PLGA. indicating the melting temperature of the crystalline pure ST. In the other side, Both DSC thermograms of empty PLGA and ST-loaded PLGA showed only one endothermic peak centered at $61.69^{\circ} \mathrm{C}$ indicating the melting temperature of PLGA (Figure 3B). ${ }^{25}$ DSC thermogram of empty PCL nanoparticles showed one endothermic peak centered at $59.59^{\circ} \mathrm{C}$ indicating the melting temperature of PCL (Figure 3C). Interestingly, ST loaded PCL NPs showed the melting peak of PCL and another broad peak centered at $193.21^{\circ} \mathrm{C}$ probably attributed to melting temperature of ST. This reveals that ST is probably encapsulated in a relatively crystalline phase (Figure $3 \mathrm{C}$ ).

\section{In Vitro Release Profiles}

Figure 4 shows the release profiles of sorafenib tosylate from ST/PCL NPs and ST/PLGA NPs in neutral medium ( $\mathrm{pH}$ 7.2) and acidic medium ( $\mathrm{pH}$ 5.2). Generally, a sustained release profile of ST from both nanoparticles was observed. In neutral medium ( $\mathrm{pH} 7.2)$, the driven mechanism of release of ST from the nanoparticles is drug diffusion. Release of ST from both formulations in neutral media is slow with maximum release of $27.9 \%$ and $31.2 \%$ from ST/PCL and ST/PLGA, respectively (Figure 4). This is probably due to the hydrophobicity of ST. In acidic medium ( $\mathrm{pH}=5.2)$, faster release rates of ST from both nanoparticles were observed with maximum release of $46.3 \%$ and $61.3 \%$, from ST/PCL and ST/ PLGA, respectively (Figure 4). Generally, a steady amount of the released ST from both formulations was observed after $48 \mathrm{~h}$. The release of ST from ST-PLGA NPs is faster than that from ST/PLGA in both neutral and acidic media. This is mainly because PLGA NPs are smaller in size, have uniform size and characterized with higher hydrophilicity due to $50 \%$ composition of the hydrophilic glycolic acid unites.

\section{Cell Viability by MTT Assay}

To assess the cytotoxic effects of the proposed models, hepatocellular carcinoma HepG2 cells were cultured and incubated with formulations of different concentrations of sorafenib tosylate $(5-30 \mu \mathrm{g} / \mathrm{mL})$. Selected cells were incubated with formulations followed by exposure to $\gamma$ irradiation using cesium-137 $\left({ }^{137} \mathrm{Cs}\right)$ with a radiation dose of $6 \mathrm{~Gy}$. In this work, the half-maximal inhibitory concentration $\left(\mathrm{IC}_{50}\right)$ of $19.2 \mu \mathrm{g} / \mathrm{mL}$ of sorafenib tosylate free drug was estimated from the dose-response curves. This value matches well with the previously reported value $(17.5 \mu \mathrm{g} / \mathrm{mL}) .{ }^{10}$ Free drug samples were prepared 

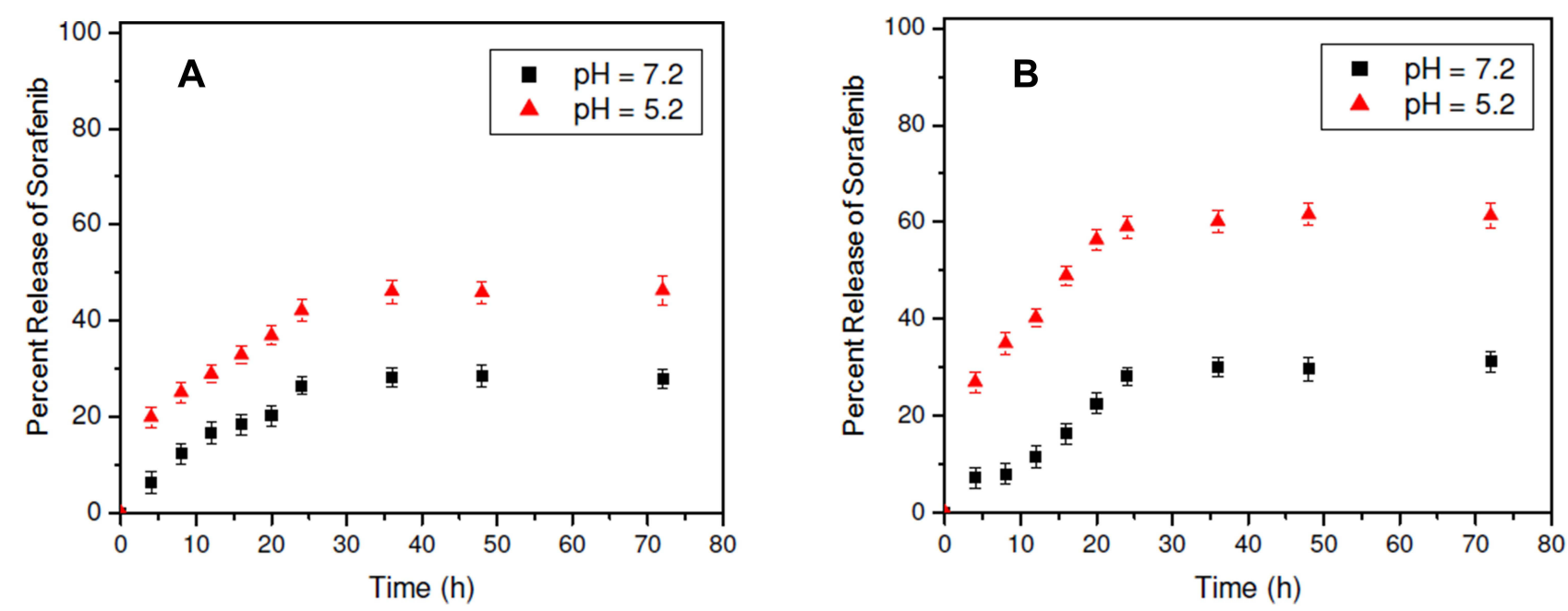

Figure 4 In vitro release profiles of ST from ST/PCL and ST/PLGA in neutral and acidic media.

by dissolving sorafenib tosylate in dimethyl sulfoxide (DMSO) and stored as stock solution at $-20^{\circ} \mathrm{C}$. According to gold analysis, the corresponding gold concentrations were found to be in the range of (1.2-7.2 $\mu \mathrm{g} / \mathrm{mL})$. HepG2 cells were cultured and incubated with the formulations for $48 \mathrm{~h}$ before processing MTT assay. $\mathrm{IC}_{50}$ of sorafenib tosylate in ST/PCL, ST/PLGA, ST/ PCL+6 Gy, ST/PLGA+ 6 Gy were found to be 12.7 , $10.3,8.9$, and $4.9 \mu \mathrm{g} / \mathrm{mL}$, respectively. Inclusion of ST in PCL and PLGA NPs significantly reduced the $\mathrm{IC}_{50}$ values of ST, compared to the free drug. This evidences the crucial role of the nanocarrier in the cellular internalization of ST molecules and subsequently their

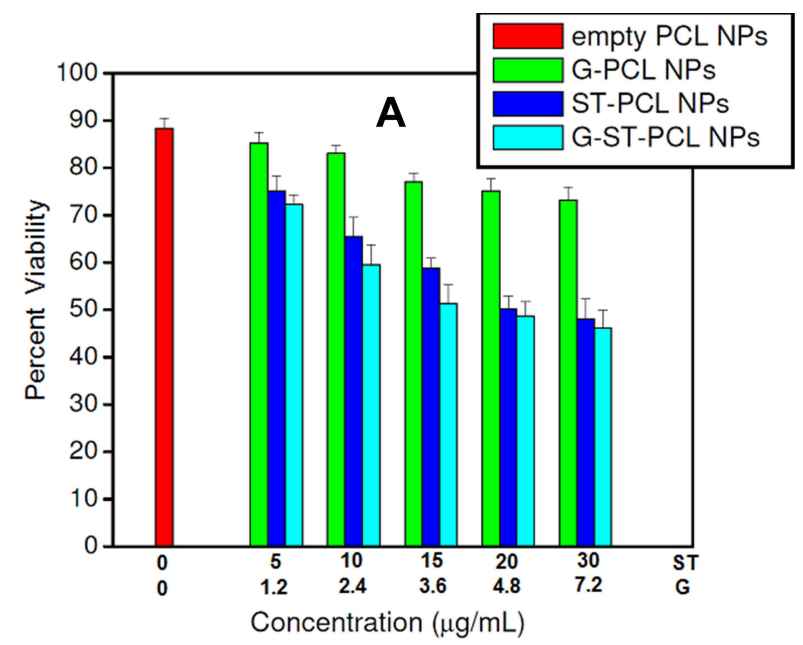

cytotoxic actions. The cell viability results are shown in Figures 5 and 6. The cell viability results are summarized in the next two parts.

\section{Treatment Without External Radiation}

Cell viabilities obtained after incubation of HepG2 cells with the prepared nanoprobes without applying an external radiation represent the pure chemical cytotoxicity of the formulations as single treatment modality (Figure 5). Empty PCL NPs and PLGA NPs showed high biocompatibility to HepG2 cells and about $90 \%$ of the cells remain viable. G/PCL NPs or G/PLGA NPs are relatively nontoxic to HepG2 cells at low concentrations of gold

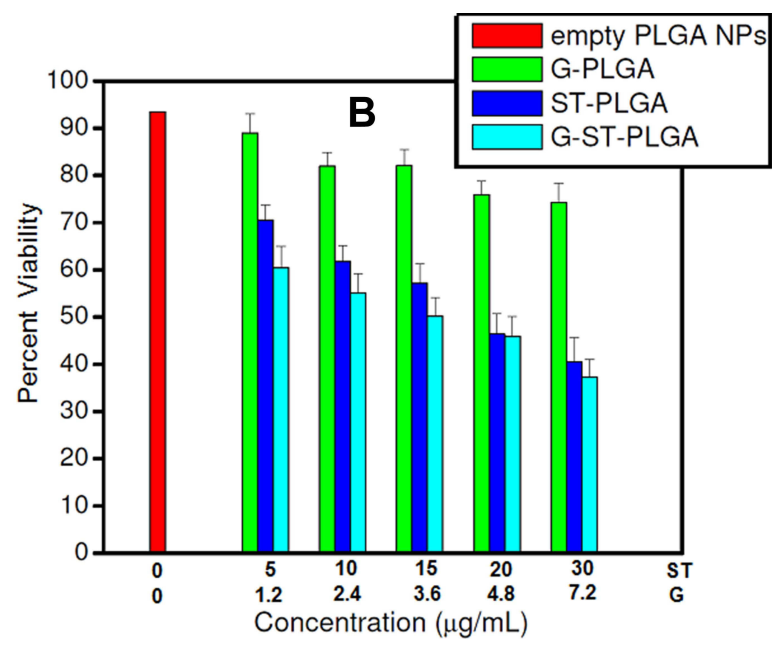

Figure 5 Viability of HepG2 cells after incubation with different PCL NPs and PLGA NPs for 48 h without irradiation. Test concentrations of ST in the nanoparticles were chosen according to $\mathrm{IC}_{50}$ of ST, lyophilized NPs were weighed and the corresponding gold concentration were calculated according to gold analysis in the nanoparticles. Notes: For the combined models, X axis represents the conc. of G and ST. However, for G/polymer NPs, conc. of ST is zero. Similarly, for ST/polymer NPs, conc. of gold is zero. 

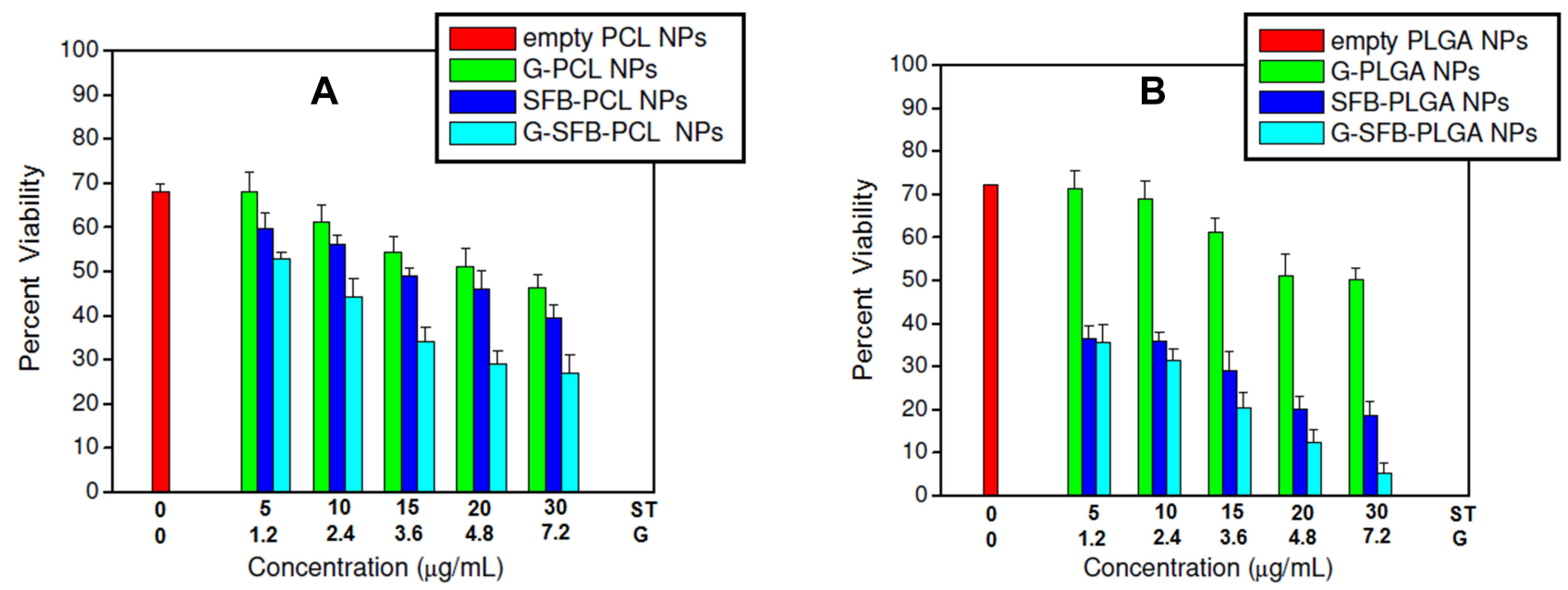

Figure 6 Viability of HepG2 cells after incubation with different PCL NPs and PLGA NPs for 48 h followed by $\gamma$-radiation (6 Gy). Test concentrations of ST in the nanoparticles were chosen according to $\mathrm{IC}_{50}$ of ST, lyophilized NPs were weighed and the corresponding gold concentration were calculated according to gold analysis in the nanoparticles.

Notes: For the combined models, X axis represents the conc. of G and ST. However, for G/polymer NPs, conc. of ST is zero. Similarly, for ST/polymer NPs, conc. of gold is zero.

nanoparticles $(<3.6 \mu \mathrm{g} / \mathrm{mL})$. Higher concentrations of gold nanoparticles induced a moderate cytotoxicity and about $75 \%$ of the cells remain viable. Treatment with sorafenib containing nanoparticles (ST/PCL or ST/PLGA) induced a clear dose-dependent chemical cytotoxicity to HepG2 cells. ST/PLGA induced a relatively higher cytotoxicity than ST/PCL at the same concentration levels of ST. Treatment with G+ST/PCL and G+ST/PLGA nanoparticles exhibited cytotoxic actions close to that induced by ST/PCL and ST/PLGA, respectively and this is attributed to the low cytotoxicity of the biocompatible pegylated gold nanoparticles.

\section{Treatment Followed by Irradiation (6 Gy)}

Treatment of cells with empty PCL NPs or PLGA NPs followed by irradiation with 6 Gy resulted in a radiationinduced cytotoxicity and only less than $70 \%$ of the cells remain viable. This pure radiation effect is probably due to necrosis of the cells due to radiation-induced-generation of free radicals. ${ }^{11,25}$ This action was significantly enhanced in G/PCL and G/PLGA as a result of gold-sensitized enhancement of the radiobiological response of HepG2 cells with less than $60 \%$ of the viable cells. This effect is dependent in gold concentration. Treatment of the cells with ST/PCL or ST/PLGA followed by irradiation with 6 Gy, resulted in significantly increased cytotoxicity in a concentration-dependent manner. This action is attributed to the chemical action of ST and nonsensitized radiation.
Treatment of HepG2 cells with G+ST/PCL or G+ST/ PLGA followed by exposure to a radiation dose of 6 Gy resulted in the highest cytotoxicity with less than $10 \%$ of viable cells. This is due to combination ST chemotherapeutic actions in synergism with gold-sensitized radiation action. In all treatments, PLGA nanoparticles exhibited cytotoxic actions higher than the corresponding PCL nanoformulations. Eventually, the lactide/glycolide ratio (50\%:50\%) provides the feasibility of controlling the degradation rate of PLGA in vitro and in vivo and, subsequently, the drug release kinetics. ${ }^{26}$ Drug-loaded PLGA nanocapsules (NCs) are characterized with drug sustained release in vitro and, therefore, enhanced cytotoxic actions. $^{27}$

\section{Flow Cytometry Using Annexin V/PI Double Staining}

In the early stages of apoptosis, phosphatidylserine (PS) transform to the outer layer of the cell membrane. Since annexin- $\mathrm{V}$ has a high affinity to bind to (PS), changes in the fluorescence of annexin- $\mathrm{V}$ are considered as a sensitive measure of the early stages of apoptosis. In the initial stages of apoptosis, the cell membrane remains intact, while in the later stages, the cell membrane loses its integrity and becomes leaky. Therefore, the measurement of annexin- $\mathrm{V}$ binding to the cell surface can be performed simultaneously with a dye-exclusion test such as propidium iodide (PI). This makes it available to establish the integrity of the cell membrane and thereby determines the 
stage of apoptosis. ${ }^{28}$ In this work, the influence of the proposed combinatorial models on the chemo- and radiotherapeutic indices of HepG2 cells was studied. The cellular apoptosis and necrosis were analyzed using flow cytometry using annexin V/PI double staining. (Figures 7 and 8). In addition to the untreated cells (control) and the cells treated only with 6 Gy radiation, another cells were treated with the prepared nanoformulations (G-ST/PCL and G-ST/PLGA) without or with a subsequent irradiation of 6 Gy. Concentrations of ST and G in the test groups were 10 and $2.4 \mu \mathrm{g} / \mathrm{mL}$, respectively. UT HepG2 cells exhibited only low levels of apoptosis with $0.5 \%$ cells in
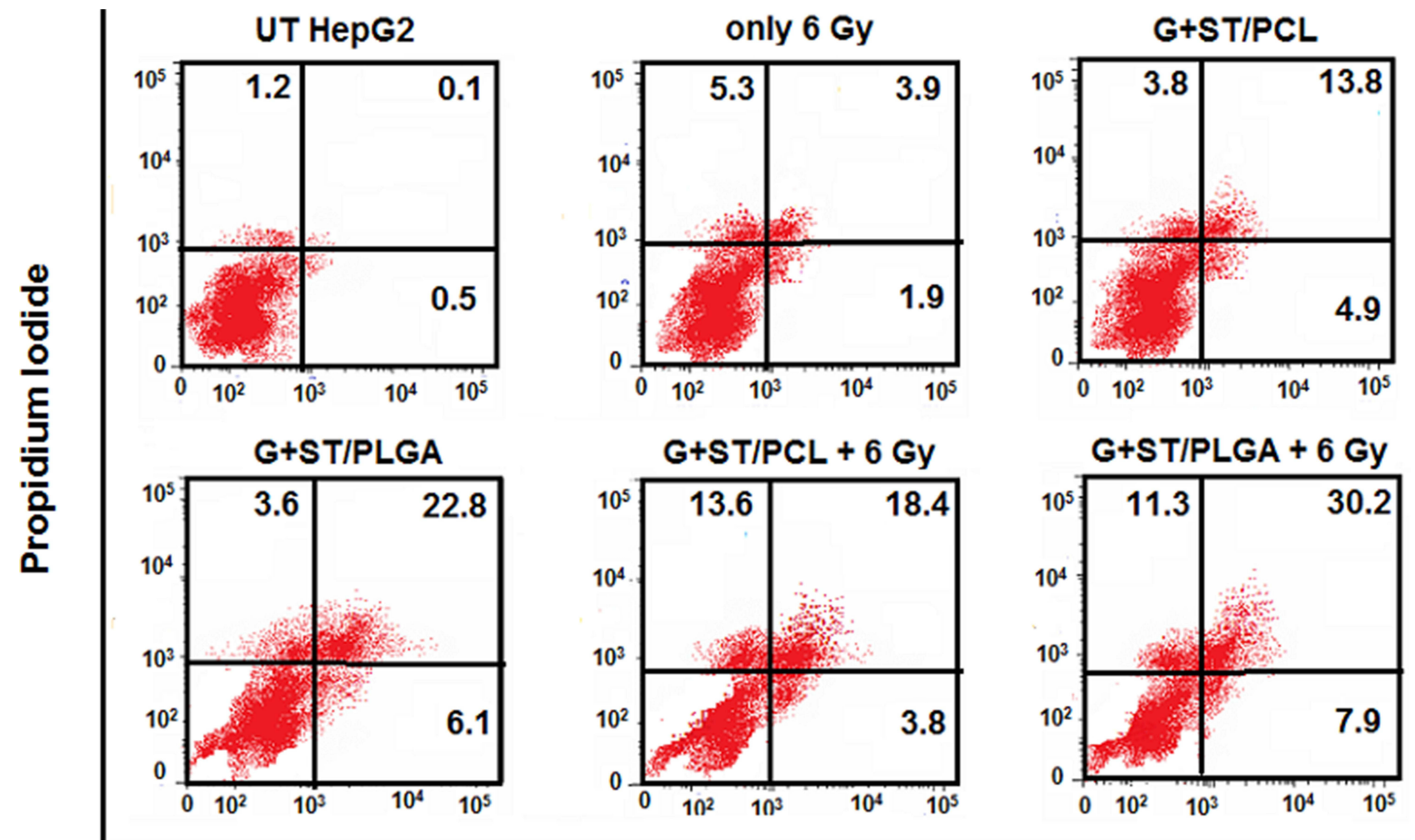

\section{Annexin-V FITC}

Figure 7 Flow cytometric analyses of the cellular apoptosis and necrosis in HepG2 cell lines following treatments with the prepared nanoformulations compared to the untreated cells using annexin V/PI double staining.

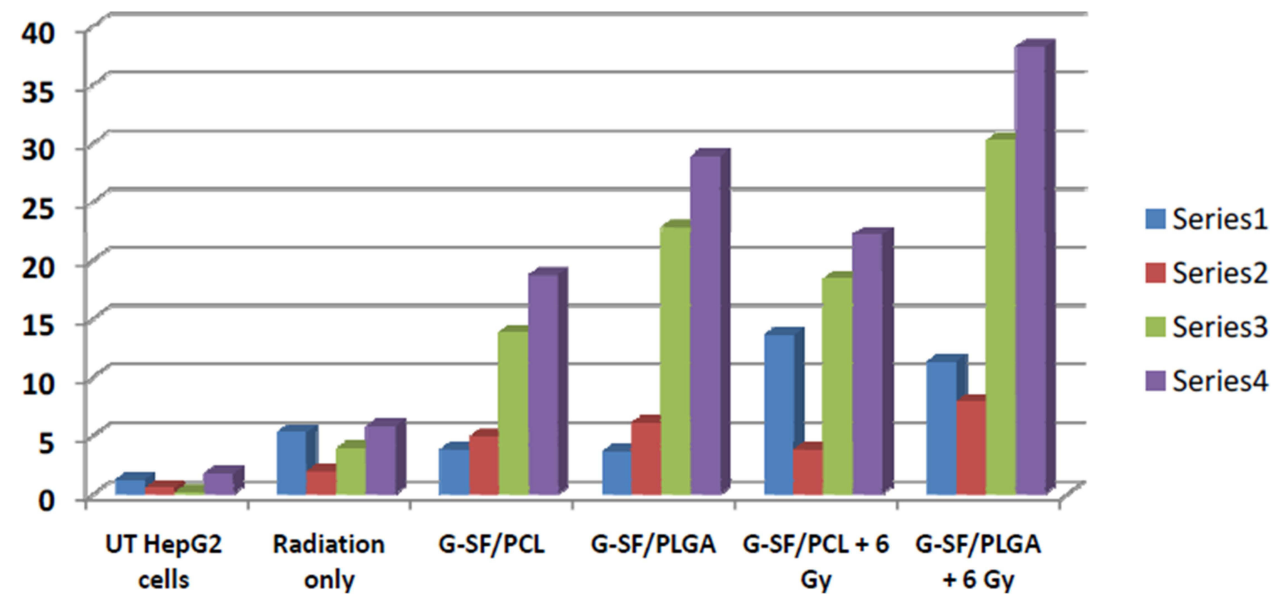

Figure 8 Illustrative diagram for the cellular apoptosis and necrosis in HepG2 cell lines following treatments with the prepared nanoformulations compared to untreated cells using flow cytometry using annexin V/PI double staining. 
early apoptosis, $0.1 \%$ in late apoptosis and $1.2 \%$ being necrotic (Figures 7 and 8 ). About $98.2 \%$ of the untreated cells remain viable. For HepG2 cells treated only with radiation dose of $6 \mathrm{~Gy}, 88.9 \%$ of the total cell population is still viable, while only $5.8 \%$ apoptotic cells and $5.3 \%$ necrotic cells were observed (Figures 7 and 8) Thus, no significant apoptotic-inducing effects are observed after radiotherapy alone. ${ }^{23}$ All nanoformulations induced a high level of apoptosis compared to untreated cells and cells treated only with radiation. Treatment of HepG2 cells with $\mathrm{G}+\mathrm{ST} / \mathrm{PCL}$ and $\mathrm{G}+\mathrm{ST} / \mathrm{PLGA}$ without irradiation induced low levels of early apoptosis since gold nanoparticles generally exhibit slight toxicity by apoptosis. ${ }^{23}$ However, these treatments exhibited high levels in late apoptosis, probably due to release of ST from the polymeric nanoparticles. For the combined treatment models $(\mathrm{G}+\mathrm{ST} / \mathrm{PCL}+6 \mathrm{~Gy})$ and $(\mathrm{G}+\mathrm{ST} / \mathrm{PLGA}+6 \mathrm{~Gy})$, both models showed high necrosis levels (15.1 and 16.2, respectively) This is mainly attributed to the gold-sensitized radiobiological cytotoxic actions on the cells. It is well established that gold nanoparticles improve the generation of hydroxyl radicals during radiation treatment. ${ }^{29}$ These free radicals react with and damage nucleic acids, proteins, and lipids of the plasma membrane, and thus GNPs are considered responsible for radiation-induced necrosis and direct death of the cells. PLGA NPs either without or with a radiation dose of 6 Gy induced apoptosis and necrosis levels significantly higher than those induced by PCL NPs. This clearly evidences the good impact of PLGA as a nanocarrier in therapeutic and radiotherapeutic indices of sorafenib tosylate and gold nanoparticles. It is noteworthy to mention that PLGA NPs are uniform in size, has lower glass transition (Tg) and higher hydrophilicity due to $50 \%$ glycolic acid composition and, therefore, exhibited better release in the first $48 \mathrm{~h}^{30}$

\section{Cell Cycle Analysis by Propidium lodide (PI) Staining}

To investigate the growth inhibition of the prepared nanoformulations, analyses for apoptosis and necrosis using annexin FITC and propidium iodide staining was carried out (Figure 9 and Table 3). Samples included the untreated HepG2 cells (UT) and the cells treated with nanoparticles comprising sorafenib tosylate $(15 \mu \mathrm{g} / \mathrm{mL})$ and gold nanoparticles $(3.6 \mu \mathrm{g} / \mathrm{mL})$ without or with exposure to a radiation dose of 6 Gy (Figure 9 and Table 3). Proliferation inhibition was seen as early as $96 \mathrm{~h}$ after first exposure. ${ }^{24}$ All formulations inhibited the growth of HepG2 cells by increasing the population of cells in $\mathrm{G}_{0} / \mathrm{G}_{1}$ -phase $(P<0.004)$ with a corresponding decrease in the number of cells in S-phase $(P<0.005)$ and $\mathrm{G}_{2} / \mathrm{M}$-phase $(P<0.234)$ compared to UT (Figure 9). Cell cycle arrest in G2/M-phase involves disruption of the tubulinmicrotubule equilibrium, ${ }^{31}$ suggesting that $\mathrm{G} 2 / \mathrm{M}$ arrest may have a role in the inhibition of microtubule dynamics. All formulations significantly increased the amount of apoptosis in HepG2 cells vs the untreated samples, as indicated from the significant increase in ( $\%$ sub- $\left.\mathrm{G}_{1}\right)$ (Table 3). Importantly, the combined treatment models exhibited elevated necrosis and apoptotic levels and evidences the synergistic actions of the combined (chemoradio) treatment model. Necrosis/apoptosis results match well with the cell viability results obtained by MTT assay for the nanoparticles comprising the same concentrations of ST and $\mathrm{G}$ in the test groups were 10 and $2.4 \mu \mathrm{g} / \mathrm{mL}$,

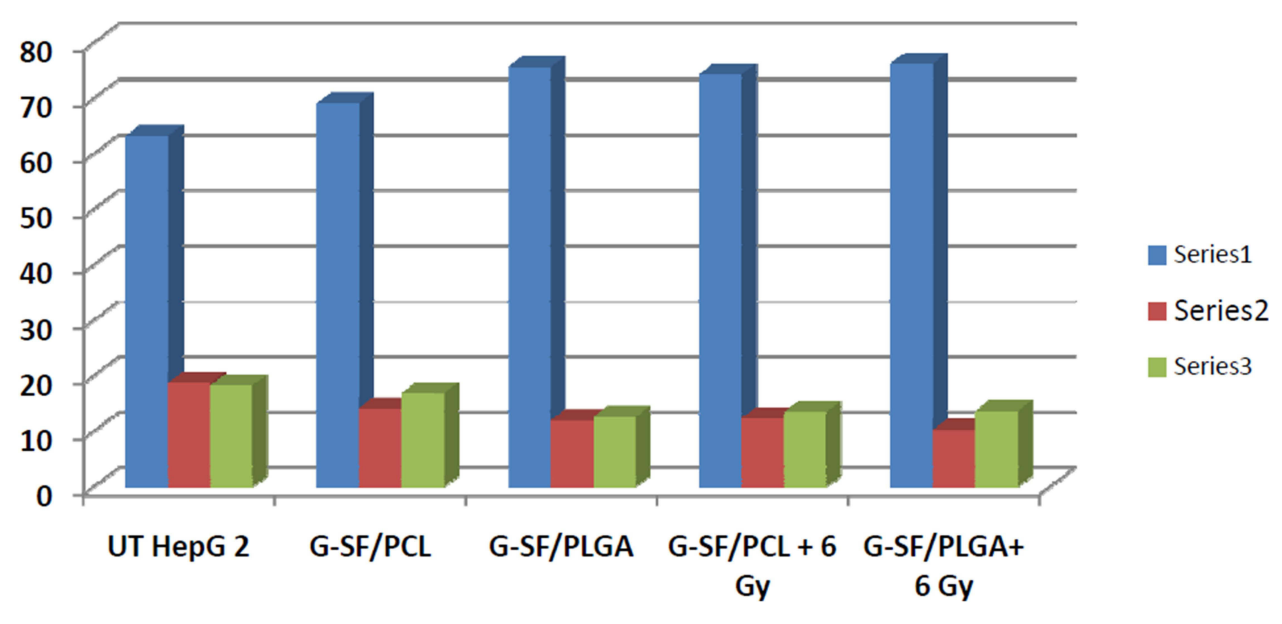

Figure 9 Analysis of cell cycle perturbation in HepG2 cell line following treatments with the prepared nanoformulations compared to untreated cells. 
Table 3 Data of Cell Cycle Analysis Perturbation in HepG2 Cell Line Following Treatments with the Prepared Nanoformulations Compared to Untreated Cells

\begin{tabular}{|l|c|c|c|c|}
\hline Treatment & $\% \mathbf{G}_{\mathbf{0}}-\mathbf{G}_{\mathbf{~}}$ & $\% \mathbf{S}$ & $\%_{\mathbf{G}_{\mathbf{2}}} / \mathbf{M}$ & $\%$ Sub-G \\
\hline UT HepG 2 & 63.2 & 18.6 & 18.2 & 1.92 \\
G+ST/PCL & 69.1 & 14.1 & 16.8 & 16.29 \\
G+ST/PLGA & 75.6 & 11.9 & 12.5 & 23.88 \\
G+ST/PCL+6 Gy & 74.3 & 12.3 & 13.4 & 27.23 \\
G+ST/PLGA+6 Gy & 76.2 & 10.2 & 13.6 & 33.04 \\
\hline
\end{tabular}

respectively. It can be concluded that all treatment models inhibited the proliferation HepG2 cells at certain extents and higher than UT cells and cells treated only with radiation. Sorafenib tosylate induces cell cycle arrest. ${ }^{24}$ It is well established that ST induces growth inhibition and apoptosis in human HCC cells by inhibiting the RAF/ MEK/ERK signaling pathway. ${ }^{7}$ Interestingly, the total apoptosis induced by PLGA NPs is higher than that induced by PCL NPs, This evidences again that PLGA is a better nanocarrier for both ST and gold nanoparticles than PCL.

\section{Mitochondrial Membrane Potential (MMP)}

The expression of glycoproteins in the mitochondrial inner membrane renders it negatively charged. ${ }^{32}$ A large accumulation of protons out of the inner membrane caused trans-membrane potential. Flow cytometric analysis of MMP was used to predict alterations in the MMP of the HepG2 cell line following treatments with the prepared nanoformulations compared to untreated cells. The obtained results (Figure 10) demonstrate that UT cells accumulated the MitoNIR dye in the mitochondria, resulting in increased red fluorescence intensity; however, in apoptotic cells, the NIR staining intensity decreased due

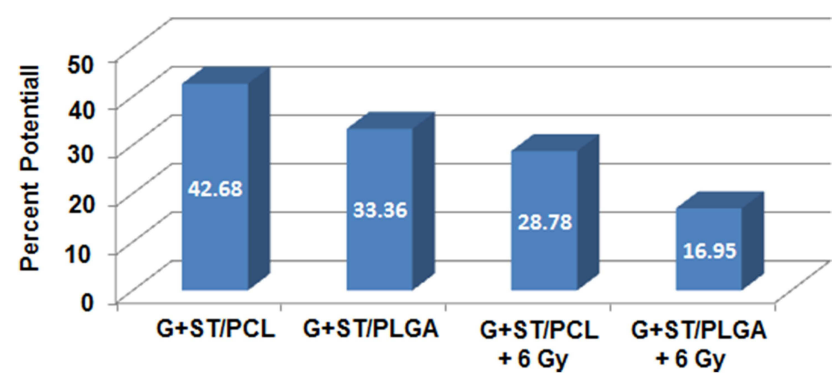

Figure 10 Changes in the MMP of the HepG2 cell line following treatments with the prepared nanoformulations compared to untreated cells as estimated by flow cytometric analysis. to the decline in MMP. ${ }^{32}$ Figure 10 demonstrates that treatment with the prepared nanoformulations significantly reduces MMP compared to that observed with untreated samples. The decline in MMP suggests a decrease in fluorescence intensity of the MitoNIR dye and thus more extensive mitochondrial membrane damage due to the larger amount of apoptosis following combined treatment.

\section{Conclusion}

The chemical and physiological properties of the polymeric nanocarriers largely affect the synergistic actions of the combined biologically active molecules. Both PLGA and PCL are capable for co-delivery of sorafenib and gold nanoparticles and exhibited elevated necrosis and apoptotic levels and evidences the synergistic actions of the combined (chemo-radio) treatment model at different levels. However, PLGA-based nanoformulations exerted higher antitumor efficacy and exhibited a greater influence on the chemo- and radiotherapeutic indices of HepG2 cells. The cytotoxic actions on HepG2 cells were assessed by cell viability assay, flow cytometry and mitochondrial membrane potential assay. The results were rationalized to the physicochemical and biological properties of each nanocarrier. Both combined treatment models exhibited elevated necrosis and apoptotic levels and evidences the synergistic actions of the combined (chemo-radio) treatment model at different levels.

\section{Acknowledgments}

We are grateful for the financial support of (National Research Centre, Dokki, Giza, Egypt) within the inhouse research project number 12020302 . We also thank Prof. Soheir S. Korraa, National Centre for Radiation Research and Technology, Egyptian Atomic Energy Authority, Cairo for kind advice.

\section{Disclosure}

The authors report no conflicts of interest in this work.

\section{References}

1. Liang P, Ballou B, Lv X, et al. Monotherapy and combination therapy using anti-angiogenic nanoagents to fight cancer. Adv Mater. 2021;33:2005155. doi:10.1002/adma.202005155

2. Yan G, Li A, Zhang A, Su Y, Liu J. Polymer-based nanocarriers for co-delivery and combination of diverse therapies against cancers. Nanomater. 2018;8:85-89. doi:10.3390/nano8020085

3. Avramovi'c N, Mandi'c B, Savi'c-Radojevi'c A, Simi'c T. Polymeric nanocarriers of drug delivery systems in cancer therapy. Pharmaceutics. 2020;12:298-302. doi:10.3390/pharmaceutics12040 298 
4. Begines B, Ortiz T, Pérez-Aranda M. Polymeric nanoparticles for drug delivery: recent developments and future prospects. Nanomaterials (Basel). 2020;10:1403-1413. doi:10.3390/nano10071403

5. Mitchell M, Billingsley M, Haley R, Wechsler M, Peppas N, Langer R. Engineering precision nanoparticles for drug delivery. Nat Rev Drug Discov. 2021;20:101-124.

6. Yang X, Li L, He D, et al. Reversal of multidrug resistance by stimuli-responsive drug delivery systems for therapy of tumor. $A d v$ Drug Deliv Rev. 2013;65:1699-1715. doi:10.1016/j.addr.2013.04.011

7. Zhang R, Wong H, Xue H, Eoh J, Wu X. Nanomedicine of synergistic drug combinations for cancer therapy - strategies and perspectives. J Control Release. 2019;240:489-503. doi:10.1016/j.jconrel.2016.06.012

8. Babos G, Biró E, Meiczinger M, Feczkó T. Dual drug delivery of sorafenib and doxorubicin from PLGA and PEG-PLGA polymeric nanoparticles. Polymers. 2018;10:895-906. doi:10.3390/polym10080895

9. Gan H, Chen L, Sui X, et al. Enhanced delivery of sorafenib with anti-GPC3 antibody-conjugated TPGSb-PCL/Pluronic P123 polymeric nanoparticles for targeted therapy of hepatocellular carcinoma. Mater Sci Eng C. 2018;91:395-403. doi:10.1016/j.msec.2018.05.011

10. Vishwakarma S, Sharmila P, Bardia A. Use of biocompatible sorafenib-gold nanoconjugates for reversal of drug resistance in human hepatoblatoma cells. Sci Rep. 2017;7:8539-8542. doi:10.1038/s41598-017-08878-y

11. Sidorov P, Naulaerts S, Ariey-Bonnet J, Pasquier E, Ballester P. Predicting synergism of cancer drug combinations using NCI-ALMANAC data. Front Chem. 2019;7:509. doi:10.3389/fchem.2019.00509

12. Darwish WM, Abdoon AS, Shata MS, Elmansy M. Vincristine-loaded polymeric Corona around gold nanorods for combination (chemo-photothermal) therapy of oral squamous carcinoma. React Funct Polym. 2020;151:104575. doi:10.1016/j.reactfunctpolym.2020.104575

13. Wang M, Li D, Li J, et al. Electrospun Janus zein-PVP nanofibers provide a two-stage controlled release of poorly water-soluble drugs. Mater Des. 2020;196:109075-109083. doi:10.1016/j.matdes.2020.109075

14. Kang S, He Y, Yu D-G, Li W, Wang K. Drug-zein@lipid hybrid nanoparticles: electrospraying preparation and drug extended release application. Colloids Surf B. 2021;201:111629-111634. doi:10.1016/ j.colsurfb.2021.111629

15. Shen X, Li T, Xie X, et al. PLGA-based drug delivery systems for remotely triggered cancer therapeutic and diagnostic applications (Review). Front Bioeng Biotechnol. 2020;8:Article 381. doi:10. 3389/fbioe.2020.00381

16. Lukasiewicz S, Mikołajczyk A, Błasiak E, Fic E, DziedzickaWasylewska M. Polycaprolactone nanoparticles as promising candidates for nanocarriers in novel nanomedicines. Pharmaceutics. 2021;13:191-204. doi:10.3390/pharmaceutics13020191

17. Haume K, Rosa S, Grellet S, et al. Gold nanoparticles for cancer radiotherapy: a review. Cancer Nano. 2016;7:8-28. doi:10.1186/ s12645-016-0021-x

18. Alhussan A, Bozdogan E, Chithrani D. Combining gold nanoparticles with other radiosensitizing agents for unlocking the full potential of cancer radiotherapy. Pharmaceutics. 2021;13:442-459. doi:10.3390/ pharmaceutics 13040442
19. Verma H, Singh P, Chavan R. Gold nanoparticle: synthesis and characterization. Vet World. 2014;7:72-77. doi:10.14202/vetworld. 2014.72-77

20. Rijcken C, Hofman J, van Zeeland F, Hennink WE, van Nostrum CF. Photosensitiser-loaded biodegradable polymeric micelles: preparation, characterisation and in vitro PDT efficacy. $J$ Control Release. 2007;124:144-153. doi:10.1016/j.jconrel.2007.09.002

21. Sharma T, Khurana R, Jain A, Katare O, Singh B. Development of a validated liquid chromatographic method for quantification of sorafenib tosylate in the presence of stress-induced degradation products and in biological matrix employing analytical quality by design (aqbd) approach. Biomed Chromatogr. 2018;32:e4169. doi:10.1002/ bmc.4169

22. Ma N, Liu P, He N. Action of gold nanospikes-based nanoradiosensitizers: cellular internalization, radiotherapy, and autophagy. ACS Appl Mater Interfaces. 2017;9:31526-31542.

23. Fathy M, Mohamed F, Elbialy N, Elshemey W. Multifunctional chitosan-capped gold nanoparticles for enhanced cancer chemo-radiotherapy: an in-vitro study. Phys Med. 2018;48:76-83. doi:10.1016/j.ejmp.2018.04.002

24. Schult C, Dahlhaus M, Ruck S. The multikinase inhibitor Sorafenib displays significant antiproliferative effects and induces apoptosis via caspase 3, 7 and PARP in B- and T-lymphoblastic cells. BMC Cancer. 2010;10:560-566. doi:10.1186/1471-2407-10-560

25. Abulateefeh S, Alkilany A. Synthesis and characterization of plga shell microcapsules containing aqueous cores prepared by internal phase separation. AAPS Pharm Sci Tech. 2016;17:891-897. doi:10.1208/s12249-015-0413-y

26. Lu J, Wang X, Marin-Muller C. Current advances in research and clinical applications of PLGA-based nanotechnology. Expert Rev Mol Diagn. 2009;9:325-341. doi:10.1586/erm.09.15

27. Acharya S, Sahoo S. PLGA nanoparticles containing various anticancer agents and tumour delivery by EPR effect. Adv Drug Deliv Rev. 2011;63:170-183. doi:10.1016/j.addr.2010.10.008

28. Hassan M, Watari H, Abu-Almaaty A, Ohba Y, Sakuragi Y. Apoptosis and molecular targeting therapy in cancer. Biomed Res Int. 2014;2014:150845.

29. Pouget J, Mather S. General aspects of the cellular response to lowand high-LET radiation. Eur J Nucl Med. 2001;28:541-561. doi: $10.1007 / \mathrm{s} 002590100484$

30. Makadia H, Siegel J. Poly lactic-co-glycolic acid (PLGA) as biodegradable controlled drug delivery carrier. Polymers (Basel). 2011;3:1377-1397. doi:10.3390/polym3031377

31. Hadfield H, Ducki S, Hirst N, McGown A. Tubulin and microtubules as targets for anticancer drugs. Prog Cell Cycle Res. 2003;5:309-325.

32. Bahman A, Abaza M, Khoushiash S, Al-Attiyah R Sequence-dependent effect of sorafenib in combination with natural phenolic compounds on hepatic cancer cells and the possible mechanism of action. Int J Mol Med. 2018;42:1695-1715.
International Journal of Nanomedicine

\section{Publish your work in this journal}

The International Journal of Nanomedicine is an international, peerreviewed journal focusing on the application of nanotechnology in diagnostics, therapeutics, and drug delivery systems throughout the biomedical field. This journal is indexed on PubMed Central, MedLine, CAS, SciSearch ${ }^{\mathbb{R}}$, Current Contents ${ }^{\mathbb{R}} /$ Clinical Medicine, $^{2}$
Journal Citation Reports/Science Edition, EMBase, Scopus and the Elsevier Bibliographic databases. The manuscript management system is completely online and includes a very quick and fair peer-review system, which is all easy to use. Visit http://www.dovepress.com/ testimonials.php to read real quotes from published authors. 